\title{
REVIEW
}

\section{Clinical implications of osteoarthritis and ageing}

\author{
David Hamerman
}

Osteoarthritis (OA) is a widely prevalent chronic condition of older individuals that affects certain diarthrodial joints. Elsewhere, I have discussed the interrelations of ageing and OA from a 'geriatric perspective', exploring basic knowledge of cellular ageing and senescence and speculating as to how these conditions may relate to cartilage changes in the osteoarthritic joint. ${ }^{1}$

\section{Morbidities and ageing: compressed or extended?}

In this article I will discuss the clincial implications of $\mathrm{OA}$ in relation to an ageing population. In an earlier Leader in this journal, Badley considered the impact on the specialty of rheumatology of an enlarging ageing population with a high prevalence of rheumatic disorders in the United Kingdom. ${ }^{2}$ While the designation of those aged 65 and over as elderly may appear 'arbitrary and imaginary' and a convenience for classification purposes, demographic projections show a continuing increase in this population that will exceed $20 \%$ by the fourth decade of the twenty first century. Those aged 85 and over represent the fastest growing segment of the elderly and their numbers, according to one estimate, will approach five million at that time (figure) ${ }^{4}$ and may be even greater. ${ }^{5}$ While the upper age limit for the end of life seems relatively fixed, ${ }^{6}$ old age is extending towards that limit. Women

Bronx, NY 10467, USA

D Hamerman

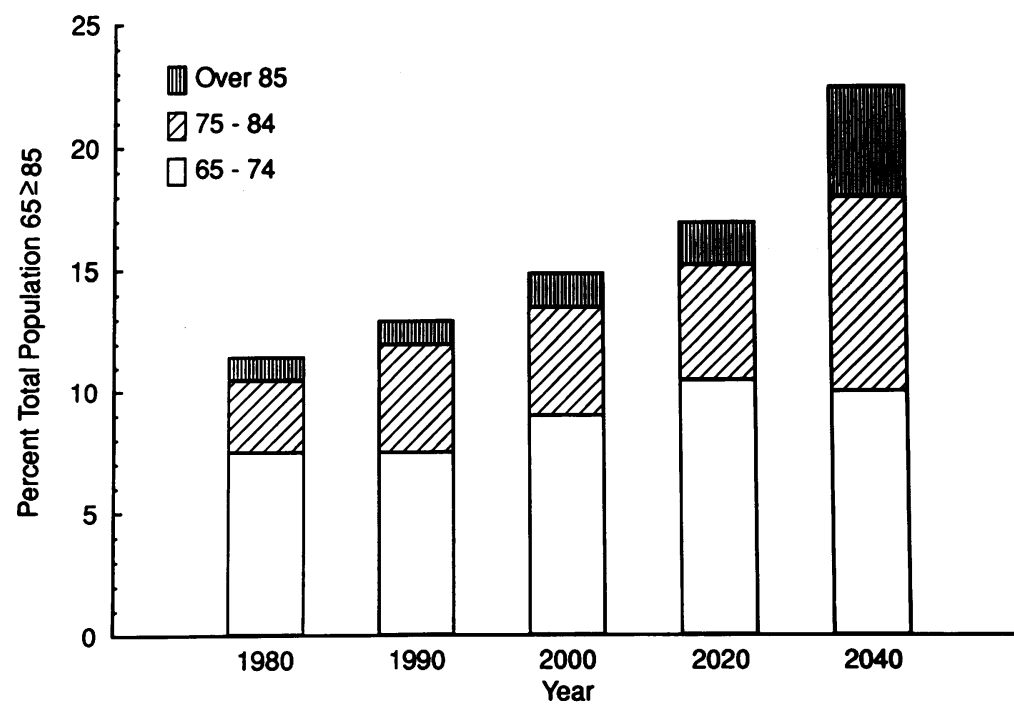

Graphic representation of population projections involving the elderly. Those older than 85 years, sometimes designated the oldest-old or extreme aged ${ }^{5}$ will represent the fastest growing segment of the elderly population in the early decades of the twenty first century (data derived from Mc Ginnis $^{4}$ ). especially can expect increasingly to achieve an age approaching 85 and men perhaps a few years less. The implications relating to the health of the very old in comparison with those aged 65-75, has prompted a distinction between the 'oldest-old' or extreme aged to include the former group, and the 'young-old' to designate the latter group. ${ }^{5}$

In a population that is growing very old, medical conditions or morbidities (table 1) become increasingly manifest. ${ }^{5}$ There is much debate about the relation of ageing and these diseases, whether or not they are 'inevitable', how they are associated with the ageing processes, and the influence of genetic and environmental factors on their expression. ${ }^{7-9}$ For a much longer lived population, the critical health issue is whether the expression of age related morbidities will eventually be compressed into the last years of a long life of good quality, or whether, even if postponed, there will be an extension of morbidities through many years of longer life. Those who support the prediction of a compression of morbidity cite medical advances and widely observed health practices-including prudent diet, exercise, maintenance of an ideal weight, cessation of smoking, and moderation in alcohol use, all of which have a positive impact on health. ${ }^{10}$ The alternative possibility, extension of morbidities, seems currently more in favour. ${ }^{11}{ }^{12} \mathrm{~A}$ delay in the expression of age associated conditions is not the same as their elimination, and still raises prospects for their contribution to health burdens carried for many more years, with the reduction of active life expectancy. ${ }^{13}$ While functional decline is not inevitable with advancing age, nevertheless evidence for limitations in activities can be cited to indicate the trend. Between the ages of 65 and 74 , about $25 \%$ of older persons are unable to perform a major activity, while about $50 \%$ of those 85 and over are unable to do so. ${ }^{14}$ In another study, more than $50 \%$ of women aged 80 and over required assistance with activities of daily living (ADL) while at the age of 65 only $20 \%$ did. ${ }^{15}$ Among those living in the community, inability to perform one or more of five basic ADLs increased from $5 \cdot 7 \%$ in those aged $65-75$, to $10 \cdot 8 \%$ in those of $75-84$

Table 1 Some conditions associated with advancing age

\begin{tabular}{ll}
\hline Heart disease & Dementia \\
Stroke & Osteoarthritis \\
Diabetes & Osteoporosis \\
Cancer & Hip fracture
\end{tabular}

In addition, there are a number of so-called geriatric syndromes, such as hearing and visual impairments, falls, and incontinence 
years, and to $25.9 \%$ in those 85 and older. ${ }^{12}$ Age related decline is also reflected in nursing home occupancy, which increases from $5 \%$ at 65 years of age to $22 \%$ at 85 years and over. ${ }^{14}$

\section{Prevalence of OA in the very elderly} Age is the greatest risk factor for OA. ${ }^{16-18}$ With the emergence of symptomatic and radiographic OA in later life, however, uncertainty remains whether the incidence continues to increase to extreme old age. Some studies suggested that this is the case while others reported little change after the age of $70 .{ }^{19} \mathrm{~A}$ prevalence rate in the oldest-old comparable to that in the young-old in some studies could be explained by different groups of subjects under review, and by the death of the oldest subjects who would have manifested OA had they survived. For example, OA may not appear to increase with extreme age because of the life shortening potential of obesity. After the age of 65 , 'the majority of adults in the industrialized world are obese' ${ }^{20}$ and obesity appears to be a risk factor for knee $\mathrm{OA}^{17}$ and possibly bilateral hip disease, ${ }^{21}$ yet it is also associated with an earlier mortality from cardiovascular diseases. ${ }^{22}$

A further problem in determining the prevalence of $\mathrm{OA}$ is defining this condition in the community. ${ }^{23}$ Hadler has proposed that 'painful knees' are widespread and 'osteoarthritis' is not necessarily the problem. $^{24}$ The association of knee pain with disability in older community residents has also been noted by McAlindon et al, but pain as a marker of OA 'might reasonably be questioned'. ${ }^{25}$ The 'discordance between the presence of radiographic changes and the presence of symptoms' ${ }^{26}$ does not provide reassurance for the diagnosis of OA, yet the radiograph must continue to be an important, if not the, key diagnostic modality. ${ }^{27} 28$ There may be a spectrum of knee conditions in the elderly compatible with definite OA, 'incipient $\mathrm{OA}^{\prime}$ ', or ageing: radiographic evidence of severe $\mathrm{OA}$ and knee pain associated with major restrictions in lower extremity functions; ${ }^{16}$ painful knees without radiographic signs of OA and with a modest decrement in physical function; or occasional complaints without radiographic findings, with intermittent mild limitations in functions. ${ }^{1}$

Among the conditions noted in table 1, OA is unique in having no mortality, ${ }^{19}$ aside from the iatrogenic effects of non-steroidal antiinflammatory drugs. ${ }^{29}$ This means that if the expression of cancer, heart disease, and stroke-the major lethal conditions of old age $^{13}$-are postponed, mortality will also be delayed, and OA may be even more prevalent in this very old group. Individuals with late life arthritis appeared to have more associated chronic diseases than those without arthritis. ${ }^{19}$ Radiographic studies of the hands and feet indicated that by the age of 80 , changes compatible with OA are almost universal, especially the expression of Heberden's nodes. $^{30}$ In nursing home residents whose mean age was 86, we observed that the presence of Heberden's nodes correlated with symptomatic and clinically diagnosed knee OA, ${ }^{31}$ as others have noted. ${ }^{32}{ }^{33}$ In a longitudinal study, Heberden's nodes were associated with radiographic evidence of cartilage loss and the clinical diagnosis of primary generalised OA. ${ }^{34}$ Other clinicians, however, have questioned the usefulness of these distal interphalangeal joint changes as a marker for OA of weight bearing joints. ${ }^{35}$

\section{Hormonal influences: $O A$ and osteoporosis}

It is unclear at present whether ageing and OA are a continuum, or whether ageing provides a necessary condition in individuals at risk for the inception of $\mathrm{OA}$ as a 'disease biologically driven', ${ }^{1}$ separate and eventually distinct from ageing changes in the joint. Long life undoubtedly contributes to ageing changes in the joint, with repetitive impact on stiffened subchondral bone, ${ }^{32}$ but $O A$ predisposition may depend on added local factors, such as menisceal injury, crystal deposition, high body weight, extreme positions of the joint, ${ }^{36}$ and lesser degrees of exercise and joint use, ${ }^{20}$ along with systemic risk factors, as discussed by Dieppe and Kirwan. ${ }^{33}$ Older individuals accrue fat and show decline in muscle mass, a finding considered as a risk factor for $\mathrm{OA}$ in the knee, as noted above.

In the ageing individual, alterations in the content or functions of growth factors locally in the joint, or brought to the joint in the circulation, may affect the capacity of cartilage abrasions to heal or regulate new bone formation, and in individuals at risk joint changes may progress to $\mathrm{OA} .{ }^{37}$ Concentrations of growth hormone and insulin like growth factor (IGF-1) have received much attention because of their anabolic effects on cartilage and bone. ${ }^{38}$ In some studies no correlation was reported between radiographic changes in knee OA and serum IGF-1 values, ${ }^{39}$ while a prospective study found a relation between IGF-1 concentrations and osteophyte growth but not joint space narrowing. ${ }^{40}$ IGF binding protein-3 appeared to be present in greater concentrations in subjects with $\mathrm{OA}$ than in controls, ${ }^{41}$ opening an area for further study and interpretation. IGF-1 is controlled by growth hormone, and it is of interest that the prevalence of radiographic OA is low in elderly patients with growth hormone deficiency. ${ }^{42}$ Decreased concentrations of growth hormone are observed in some frail elderly individualsa finding that has prompted short term administration of this hormone in a number of studies, with subsequent increases observed in muscle mass and bone mineral content in the lumbar spine. ${ }^{43}$ Greater bone density in the primary generalised variant of $\mathrm{OA},{ }^{44}$ or in cases with radiographic evidence of osteophytes, ${ }^{45} 46$ may in part be attributable to greater circulating concentrations of IGF- $1,{ }^{41}$ and to increased content of this growth factor in bone. ${ }^{47}$ In the very elderly, decreased concentrations of circulating IGF-1 have been found in osteoporosis, ${ }^{41}$ and, in contrast to OA, reduced bone density is the rule, with the risk 
of hip fracture. The role of oestrogens also needs to be further explored in $\mathrm{OA}$ as it has been in osteoporosis, since lack of oestrogen appears to be the principal inciting factor in postmenopausal osteoporosis. Conversely, oestrogen availability in some patients with generalised $\mathrm{OA}^{48}$ may inhibit osteoblast release of interleukin-6, which appears to act on osteoclasts to promote bone resorption: ${ }^{49}$ thus bone density may be preserved or enhanced in OA, with a reduced risk of hip fracture.

\section{OA and disability in the very elderly}

Rheumatologists in consultative hospital practice may observe $\mathrm{OA}$ in a more restrictive fashion than their colleagues in community based practice where the practitioner will be aware of the social setting, and to what extent patient and caregiver can manage successfully. ${ }^{2}$ The impact of lower extremity OA on the very elderly must be considered in association with age related comorbidities: maintenance of functional capacity depends on the individual's initial level of function, lower weight, and lack of cardiovascular disease. ${ }^{50} 51$ Impaired cardiorespiratory function reduces walking ${ }^{52}$ and exercise tolerance, and would be additive to potential lower limb disability resulting from OA. Similarly, neurological and sensory sequelae of cerebrovascular diseases and diabetes produce difficulty in ambulation and with ADLs. Guccione et al have attempted to separate the contributions to disability of multiple morbidities in conjunction with knee OA. ${ }^{53}$ Individuals with symptomatic knee OA with radiographic evidence of osteophytes, or asymptomatic knee OA with severe radiographic changes of large osteophytes ${ }^{54}$ and joint space narrowing, have increased risk for dependence in those ADLs requiring use of the lower extremities. ${ }^{53}$ Some indices of functional performance and a broader perspective on disability in relation to arthritis are discussed elsewhere. ${ }^{55-57}$ Seven measures of disability, two explicitly involving the lower extremities and five related to functional tasks requiring use of both upper and lower extremities were assessed in individuals with a range of age related medical conditions. Table 2 summarises the main findings. ${ }^{55}$ The largest proportions of disability were attributable to stroke, depressive symptomatology, heart disease, and knee OA. In addition to age, psychological factors are strongly associated with knee pain and disability in OA. ${ }^{58}$

Can interventions by individuals themselves offset the potential for disability from lower extremity OA? Measures begun years earlier,

Table 2 Association of dependency with certain medical conditions ${ }^{55}$

\begin{tabular}{ll}
\hline Medical condition & $\begin{array}{l}\text { Number of tasks } \\
\text { associated with } \\
\text { dependency }\end{array}$ \\
\hline Stroke & 7 \\
Depression & 5 \\
Hip fracture & 5 \\
Knee OA & 4 \\
Heart disease & 4 \\
Congestive heart failure & 4 \\
Pulmonary disease & 4 \\
\hline
\end{tabular}

such as weight reduction, exercise, and limiting chances for trauma to the joints, might have served in the capacity of secondary or even primary prevention ${ }^{102159}$ for a condition in which health providers traditionally can offer only tertiary care.$^{19}$ Higher education appears to reduce impaired walk rate in community dwelling elders; this might be considered an intervention factor, as low education level appears to be a risk factor for other conditions, such as cardiovascular diseases and mortality and morbidity in rheumatoid arthritis. ${ }^{52}$ However, even with advanced arthritic disease in the elderly, the potential for pain reduction and improvement in ambulation has been noted as a result of supervised walking and patient education activities, ${ }^{60}$ or a physical therapy programme. ${ }^{61}$ In both of these studies on community based volunteers, within-hospital facilities were used as a means to improve staff availability and subject compliance. In the former study, the mean age of subjects was 70 years; controls received telephone contact only, possibly not sufficient for a good comparison. In the latter study, with a mean subject age of 65 years, controls were not observed. Exercise interventions were also used for nursing home residents of more advanced age, without necessarily the intent to treat OA. Exercises were carried out while individuals remained seated, limiting cardiovascular stresses. In one study (mean age 82 ), exercises included stretching and range of movement; ${ }^{62}$ in another study (mean age 90 ), dynamic quadriceps strengthening was done, with demonstrated increase in muscle mass and strength, and decrease in the time required to walk a measured distance. Of great importance, strength gains were rapidly lost again after cessation of exercise. ${ }^{63}$

\section{Conclusions}

As a larger proportion of the elderly population in developed countries increasingly lives to extreme old age, OA will be more prevalent and contribute to the impact of disability from other age associated morbidities. Medical advances and improved health practices may potentially postpone the emergence of many chronic diseases in the very elderly, but are unlikely to eliminate them. Very long life will continue to present personal challenges and major health care and social responsibilities. There are many examples cited in this paper of professionals in broad aspects of rheumatology and gerontology whose work comes together on the musculoskeletal system of the aged. Even greater collaboration is likely to occur in the future between professionals concerned with various aspects of the emerging picture of $\mathrm{OA}$ in the very elderly: epidemiology, natural history, assessment, therapies, and interventional programmes, applied earlier and designed to improve musculoskeletal functions in frail older community dwellers and nursing home residents.

Hamerman D. Aging and osteoarthritis: basic mechanisms. f Am Geriatr Soc 1993; 41: 760-70. 
2 Badley E M. Population projections and the effect on rheumatology. Ann Rheum Dis 1991; 50: 3-6.

3 Bellamy N. Treatment considerations in the elderly rheumatic patient. Gerontology 1988; 34 (suppl 1): 16-26.

4 McGinnis J M. The Tithonus syndrome: health and aging in America. In: Chernoff R, Lipschitz D A, eds. Health promotion and disease prevention in the elderly. New York: Raven Press, 1988: 1-15.

5 Taeuber C M, Rosenwaike I. A demographic portrait of America's oldest old. In: Suzman R M, Willis D P, Manton K G, eds. The oldest old. New York: Oxford University Press, 1992: 17-49.

6 Olshansky S J, Carnes B A, Cassel C. In search of Methuselah:" estimating the upper limits to human Methuselah: estimating the upper

7 Brody J A, Schneider E L. Diseases and disorders of aging: an hypothesis. $\mathcal{f}$ Chron Dis 1986; 39: 871-6.

8 Evans J G. Ageing and disease. In: Evered D, Whelan J, eds. Research and the ageing population. Ciba Foundation Symposium 134. New York: John Wiley and Sons, 1988: 38-47.

9 Forbes W F, Hirdes J P. The relationship between aging and disease: geriatric ideology and myths of senility. $\mathcal{F} \mathrm{Am}$ Geriatr Soc 1993; 41: 1267-71.

10 Fries J F. Aging, illness, and health policy: implications of the compression of morbidity. Perspect Biol Med 1988; 31: 407-28.

11 Olshansky S J, Rudberg M A, Carnes B A, Cassel C K, Brody J A. Trading off longer life for worsening health. (The expansion of morbidity hypothesis). $\mathcal{F}$ Aging Health 1991; 3: 194-216.

12 Guralnik J M. Prospects for the compression of morbidity. f Aging Health 1991; 3: 138-54.

13 Cassel C K, Neugarten B L. A forecast of women's health and longevity-implications for an aging America. West $\mathcal{f}$ Med 1988; 149: 712-7.

14 Rubenstein L Z. An overview of aging-demographics, epidemiology, and health services. In: Morley $\mathrm{J}$ E, Glick Z, Rubenstein L Z, eds. Geriatric nutrition: a comprehensive review. New York: Raven Press, 1990: $1-10$

15 Valkenburg H A. Epidemiologic considerations of the geriatric population. Gerontology 1988; 34 (suppl 1): 2-10

16 Davis M A, Ettinger W H, Neuhaus J M, Mallon K P. Knee osteoarthritis and physical functioning: evidence from NHANES 1 epidemiologic followup study. $\mathcal{f}$ Rheumatol 1991; 18: 591-8.

17 Felson D T. The epidemiology of knee osteoarthritis: results from the Framingham osteoarthritis study. Sem Arthritis Rheum 1990; 20: 42-50.

18 Peyron J G, Altman R D. The epidemiology of osteoarthritis In: Moskowitz R W, Howell D S, Goldberg V M, Mankin $\mathrm{H}$ J, eds. Osteoarthritis: diagnosis and medical surgical management, 2nd edn. Philadelphia: W B Saunders Company, 1992: 15-37.

19 Verbrugge L $M$. Disability transitions for older persons with arthritis. F Aging Health 1992; 4: 212-43.

20 Rudman D. Nutrition and fitness in elderly people. $A m \mathcal{F}$ Clin Nutr 1989; 49: 1090-8.

21 Tepper S, Hochberg M C. Factors associated with hip osteoarthritis: data from the first National Health and Nutrition Examination Survey (NHANES-1). Am $\mathcal{f}$ Epidemiol 1993; 137: 1081-8.

22 Verbrugge L M, Gates D M, Ike R W. Risk factors for disability among U.S. adults with arthritis. $f$ Clin Epidemiol 1991; 44: 167-82.

23 Spector T D, Hochberg M C. Methodological problems in the epidemiological study of osteoarthritis. Ann Rheum Dis 1994; 53: 143-6.

24 Hadler N M. Knee pain is the malady-not osteoarthritis. Ann Int Med 1992;116: 598-9.

25 McAlindon T E, Cooper C, Kirwan J R, Dieppe P A. Knee pain and disability in the community. Br $\mathcal{J}$ Rheum 1992; 31: 189-92.

26 Hadler N M. Osteoarthritis as a public health problem. Clin Rheum Dis 1985; 11: 175-85.

27 Claessens A A M C, Schouten J S A G, van den Ouweland F A, Valkenburg H A. Do clinical findings associate with radiographic osteoarthritis of the knee? Ann Rheum Dis 1990; 49: 771-4.

28 Ledingham J, Dawson S, Preston B, Milligan G, Doherty $M$. Radiographic progression of hospital referred osteoarthritis of the hip. Ann Rheum Dis 1993; 52: 263-7.

29 Fries J F. NSAID Gastropathy: the second most deadly rheumatic disease? Epidemiology and risk appraisal. rheumatic disease? Epidem

30 Kelsey J L. Prevalence studies of the epidemiology of osteoarthritis. In: Lawrence R C, Shulman L E, eds. Epidemiology of the rheumatic diseases. New York: Gower Medical, 1984: 282-8.

31 Hamerman D, Sherlock L, Damus K, Habermann E T. Research in the teaching nursing home: an approach to assessing osteoarthritis of the hips and knees. Einstein Quart F Biol Med 1988; 6: 110-9.

32 Felson D T, Radin E L. What causes knee osteoarthrosis: are different compartments susceptible to different risk factors? f Rheumatol 1994; 21: 181-2.

33 Dieppe P, Kirwan J. The localization of osteoarthritis. $\mathrm{Br} f$ Rheumatol 1994; 33: 201-4.

34 Schouten J S A G, van den Ouweland F A, Valkenburg H A. A 12 year follow up study in the general population on prognostic factors of cartilage loss in osteoarthritis of the knee. Ann Rheum Dis 1992; 51: 932-3.

35 Yazici H, Saville P S, Salvati E A, Bohn W H O Wilson P D Jr. Primary osteoarthritis of the knee and hip. Prevalence of Heberden's nodes in relation to age and sex. fAMA 1975; 231: 1256-60.

36 Cooper C, McAlindon T, Coggon D, Egger P, Dieppe P. Occupational activity and osteoarthritis of the knee. Ann Rheum Dis 1994; 53: 90-3.

37 Hamerman D. Prospects for medical intervention in cartilage repair. In: Woessner J F Jr, Howell D S, eds. Foint cartilage degradation. Basic and clinical aspects. New York: cartilage degradation. Basic and

38 George E, Sharif $M$, Dieppe P. Insulin-like growth factor-1 and biochemical markers of osteoarthritis of the knee. $\mathrm{Br}$ f Rheumatol 1993; 32: 265-8.

39 McAlindon R E, Teale J D, Dieppe P. Levels of insulin related growth factor 1 in osteoarthritis of the knee. Ann Rheum Dis 1993; 52: 229-31.

40 Schouten J S A G, van den Ouweland F A, Valkenburg H A Lamberts $S \mathrm{~W} \mathrm{~J}$. Insulin-like growth factor-1: A prognostic factor of knee osteoarthritis. $\mathrm{Br} \mathcal{7}$ Rheumatol 1993; 32: 274-80.

41 Wüster C. Growth hormone and bone metabolism. Acta Endocrinologica 1993; 128: 14-8.

42 Bagge E, Eden S, Rosen T, Bengtsson B-A. The prevalence of radiographic osteoarthritis is low in elderly patients with growth hormone deficiency. Acta Endocrinologica 1993; 129: 296-300.

43 Borst S E, Millard W J, Lowenthal D T. Growth hormone, exercise, and aging: The future of therapy for the frail elderly. F Am Geriatr Soc 1994; 42: 528-35.

44 Hordon L D, Stewart S P, Troughton P R, Wright V, Horsman A, Smith M A. Primary generalized osteoarthritis and bone mass. Br $\mathcal{f}$ Rheumatol 1993; 32: 1059-61.

45 Hannan M T, Anderson J J, Zhang Y, Levy D, Felson D T. Bone mineral density and knee osteoarthritis in elderly men and women. The Framingham Study. Arthritis Rheum 1993; 36: 1671-80.

46 Hart D J, Mootoosamy I, Doyle D V, Spector T D. The relationship between osteoarthritis and osteoporosis in the general population: The Chingford Study. Ann Rheum Dis 1994; 53: 158-62.

47 Dequeker J, Mohan S, Finkelman R D, Aerssens J, Baylink D J. Generalized osteoarthritis associated with increased insulin-like growth factor types I and II and transforming growth factor $\beta$ in cortical bone from the iliac crest. Arthritis Rheum 1993; 36: 1702-8.

48 Spector T D, Campion G D. Generalized osteoarthritis: a hormonally mediated disease. Ann Rheum Dis 1989; 48 : 523-7.

49 Horowitz M C. Cytokines and estrogen in bone: antiosteoporotic effects. Science 1993; 260: 626-7.

50 Harris T, Kovar M G, Suzman R, Kleinman J C, Feldman J J. Longitudinal study of physical ability in the oldest old. Am f Public Health 1989; 79: 698-702.

51 Crimmins E M, Saito Y. Getting better and worse. Transitions in functional status among older Americans. f Aging Health 1993; 5: 3-36.

52 Gibbs J, Hughes S, Dunlop D, Edelman P, Singer R, Chang R. Joint impairment and ambulation in the elderly. f Am Geriatr Soc 1993; 41: 1205-11.

53 Guccione A A, Felson D T, Anderson J J. Defining arthritis and measuring functional status in elders: methodological issues in the study of disease and physical disability. $A m$ f Public Health 1990; 80: 945-9.

54 Spector T D, Hart D J, Byrne J, Harris P A, Dacre J E, Doyle D V. Definition of osteoarthritis of the knee for epidemiological studies. Ann Rheum Dis 1993; 52: 790-4.

55 Guccione A A, Felson D T, Anderson J J, et al. The effects of specific medical conditions on the functional limitations of elders in the Framingham Study. $A m \mathcal{f}$ Public Health 1994; 84: 351-8.

56 Verbrugge L M. Disability. Rheum Dis Clin NA 1990; 16: 741-57.

57 Badley E M, Tennant A. Disablement associated with rheumatic disorders in a British population: problems with activities of daily living and level of support. $B r \mathcal{F}$ Rheum 1993; 32: 601-8.

58 Salaffi F, Cavalieri F, Nolli M, Ferraccioli G. Analysis of disability in knee osteoarthritis. Relationship with age and psychological variables but not with radiographic score. psychological variables but not

59 Hochberg $M$ C. Epidemiologic considerations in the primary prevention of osteoarthritis. $\mathcal{F}$ Rheumatol 1991 ; primary prevent $1438-40$.

60 Kovar P A, Allegrante J P, MacKenzie R, Peterson M G E, Gutin B, Charlson M E. Supervised fitness walking in patients with osteoarthritis of the knee. Ann Int Med 1992; 116: 529-34.

61 Fisher N M, Gresham G E, Abrams M, Hicks J, Horrigan D, Pendergast D R. Quantitative effects of physical therapy on muscular and functional performance in subjects with osteoarthritis of the knees. Arch Phys Med Rehabil 1993; 74: 840-7.

62 McMurdo M E T, Rennie L. A controlled trial of exercise by residents of old people's homes. Age Ageing 1993; 22: 11-5.

63 Fiatarone M A, Marks E C, Ryan N D, Meredith C N, Lipsitz L A, Evans W J. High-intensity strength training in nonagenarians. $\mathcal{F A M A}$ 1990; 263: 3029-43. 